\title{
The effect of a response requirement on schedule-induced aggression
}

\author{
RANDALL K. FLORY and HILLEARY D. EVERIST \\ Hollins College, Roanoke, Virginia 24020
}

\begin{abstract}
The attack behavior induced in pigeons by a fixed-ratio schedule of food reinforcement was compared with that induced by a variable-time schedule composed of the actual interreinforcement intervals of the preceding fixed-ratio schedule condition. For two of the four pigeons that exhibited schedule-induced aggression against a nearby stuffed pigeon, the response-dependent (fixed-ratio) schedule induced a higher rate of attack than did the response-independent (variable-time) schedule. For the remaining two birds, no measure of induced aggression was consistently related to either schedule condition. These results indicate that a response requirement for reinforcement is not a limiting condition for the induction of attack behavior in pigeons.
\end{abstract}

Aggressive behavior has been induced by the transition from a period of frequent food delivery to one during which food is never delivered (Azrin, Hutchinson, \& Hake, 1966) and by response-dependent as well as response-independent food schedules (Cherek, Thompson, \& Heistad, 1973; Cohen \& Looney, 1973; Flory, 1969; Webbe, DeWeese, \& Malagodi, 1974). To determine the effect of a response requirement on the occurrence of schedule-induced aggression, two studies (Cherek et al., 1973; Huston \& DeSisto, 1971) each compared the attack generated by a response-dependent schedule with that generated by a matched responseindependent schedule. Cherek et al. found that the rate of attack induced in pigeons by a response-initiated fixed-interval food schedule was either equal to or somewhat greater than that induced by a responseindependent fixed-time schedule equal in value to the mean interreinforcement duration of the responsedependent schedule condition. In an investigation of the aggressive behavior of rats against frogs, Huston and DeSisto (1971) found that the frequency of attack induced by a fixed-ratio schedule of hypothalamic electrical stimulation was greater than that occurring when brain stimulation was delivered on a responseindependent basis at fixed time periods equal to the mean interreinforcement interval of the responsedependent schedule.

So that the effects of a response requirement on

This report is based on a portion of a thesis submitted by the second author to the Graduate School of Hollins College in partial fulfillment of the requirements for the MA degree. The experiment was supported in part by the Faculty Research and Travel Committee of Hollins College. We wish to thank Eric Smith for his help with the design of the experiment and Charlotte Collings for her assistance in preparation of the manuscript. Reprints may be obtained from Randall K. Flory, Department of Psychology, Hollins College, Roanoke, Virginia 24020. The second author is now at the University of Maryland. schedule-induced aggression might be assessed as clearly as possible, the level of aggression induced by a totally response-dependent schedule should be compared with that induced by a totally response-independent schedule the interrinforcement interval of which is appropriately matched to that of the response-dependent schedule. In contrast to the totally response-dependent fixed-ratio schedule used by Huston and DeSisto (1971), the response-initiated fixed-interval schedule employed by Cherek et al. (1973) was based on a time requirement as well as on a response requirement. Furthermore, in both studies, the response-independent schedule delivered reinforcers periodically, whereas the responsedependent schedule delivered reinforcers on an aperiodic basis. The present study controlled this periodicity factor by programming the interreinforcement intervals of a totally response-dependent schedule as the actual interfood intervals of a response-independent schedule.

\section{METHOD}

\section{Subjects}

Nine male White Carneaux pigeons, ranging from 2 to 8 years of age, were maintained at $80 \%$ of their free-feeding body weights. Pigeons AC 1, AC 3, AC 4, AC 8, AC 24, and AC 25 had previously exhibited schedule-induced attack against a stuffed target pigeon. The remaining three birds had a prior history of intermittent reinforcement but none had exhibited schedule-induced attack. Each pigeon was housed individually in wood and wire cages located in a constantly illuminated room with temperature and humidity controlled.

\footnotetext{
Apparatus

One end of a pigeon chamber contained a food magazine located behind a $4.5 \times 6.0 \mathrm{~cm}$ aperture and a response key located $9.0 \mathrm{~cm}$ above the aperture. At the other end of the chamber, approximately $50.0 \mathrm{~cm}$ from the stimulus panel, was a taxidermically prepared White Carneaux pigeon, the head and throat areas of which were covered with closely cropped white rabbit fur so that the model would be more durable. A Plexiglas shield restricted the experimental subject to the area in front of the target bird, and a microswitch closed whenever a force of $55-60 \mathrm{~g}$ or more was exerted against the model's head. Only
} 
switch closures separated by at least a 100 -msec interval were recorded as discrete attacks. This contingency prevented those switch closures resulting from rebound target movements from registering as attacks. Standard electromechanical equipment arranged and recorded all experimental events.

\section{Procedure}

Prior to exposure to the stuffed target, each subject was magazine trained and then trained to keypeck on a fixed-ratio (FR) 1 food schedule. The value of the FR schedule was then progressively increased until the keypecking behavior of each subject showed patterning characteristic of FR schedules with relatively high response requirements (Ferster \& Skinner, 1957). Each subject was exposed to its particular FR schedule until no systematic upward or downward trends were observed over five consecutive sessions in the (1) mean interreinforcement interval, (2) mean pause to the first keypeck response, and (3) keypeck response rate.

Following schedule training, the target pigeon was placed in the chamber, and each subject's FR schedule continued to be in effect. After a minimum of 15 sessions, the last 5 of which showed no systematic trends in attack rate and number of FR components with at least one attack, the yellow response key was covered and a variable-time (VT) schedule was initiated. The time intervals of this response-independent schedule were the actual interreinforcement intervals produced by each subject during each of the last five sessions of the previous FR schedule condition. That is, the $\mathbf{4 0}$ interreinforcement intervals occurring in the first of the last five sessions of the FR condition constituted the 40 interfood intervals of the first session of the VT schedule condition. Similarly, the 40 interreinforcement intervals occuring in the second of the last five sessions of the FR condition constituted the 40 interfood intervals of the second session of the VT schedule condition, and so on. This 5-day series of interreinforcement intervals was repeated throughout the response-independent schedule condition. The VT schedule remained in effect for a minimum of 15 sessions, the last 5 of which showed no systematic trends in the attack rate and number of interfood intervals with at least one attack.

After attack stabilized during the response-independent condition, each pigeon's FR schedule was reinstated for a minimum of 15 sessions and until the stability criteria as previously described were met. The final experimental phase of the study was a VT schedule based on each of the last five sessions of the second FR condition. The interreinforcement intervals occurring in the last five sessions of the second FR condition constituted the interfood intervals of the second VT schedule condition. Subjects were exposed to this response-independent condition for a minimum of 15 sessions and until the stability criteria as previously described were met.

Sessions were conducted 5 days weekly and were terminated after 403 -sec presentations of mixed grain. A protective contingency, which arranged that food delivery could not occur until at least $12 \mathrm{sec}$ had elapsed since the last attack, was employed to prevent the adventitious reinforcement of attack behavior.

\section{RESULTS}

Figure 1 shows attack rates across conditions for Pigeons AC 1, AC 3, AC 24, and AC 25. Data for the remaining birds are not presented, since two did not exhibit attack, two did not display consistent FR performance during initial schedule training, and another exhibited a relatively high rate of attack which progressively decreased over 50 sessions to a near-zero level. For Birds AC 1 and AC 24, the mean attack rate based

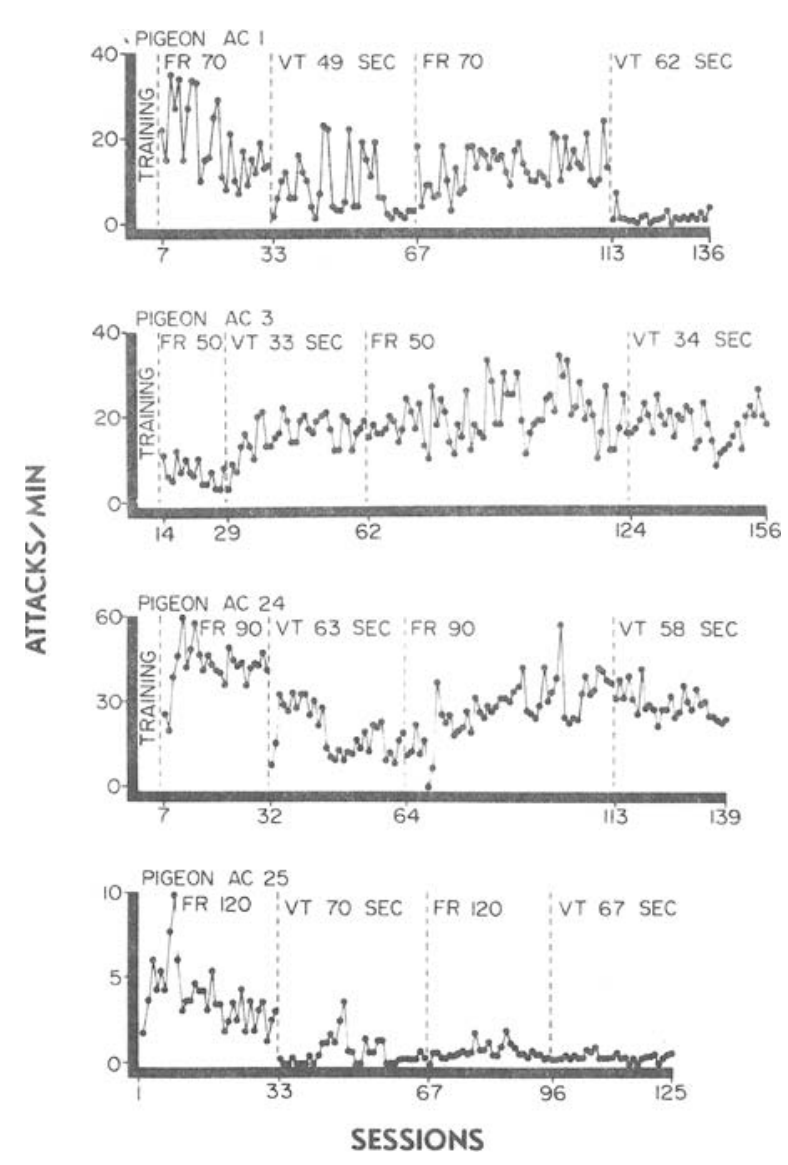

Figure 1. Session attack rates during each experimental condition for Pigeons AC 1, AC 3, AC 24, and AC 25.

on the last five sessions of the first VT schedule condition was lower than that during the last five sessions of the first FR condition. Similarly, the mean attack rates for Pigeons AC 1 and AC 24 were lower during the last five sessions of the second VT schedule condition than during the final five sessions of the second exposure to the FR schedule. For Pigeon AC 3, however, the mean rate of attack during the first response-independent schedule condition was higher than that during the preceding response-dependent condition, and the attack rate of this bird remained relatively high across the final three experimental conditions of the study. Pigeon AC 25 exhibited a lower attack rate during exposure to the first VT schedule as compared to that during the preceding FR schedule condition; the attack rate of this bird remained relatively low throughout the remainder of the study.

Figure 2 shows the number of FR or VT components in which at least one attack occurred. This measure of schedule-induced aggression is presented since it did not covary with the rate of attack for all subjects. Throughout the study, the maximum number of components in which attack could occur was 40 since the number of food presentations was held constant in all experimental 


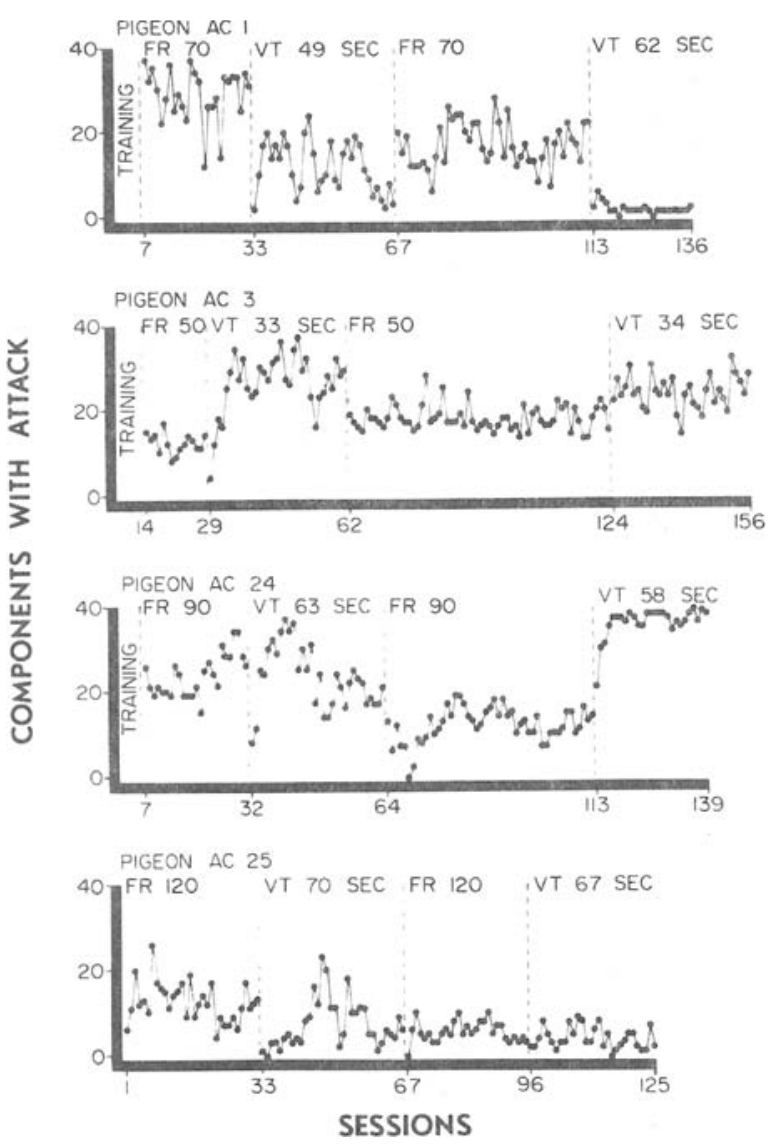

Figure 2. Number of session fixed-ratio and variable-time schedule components in which at least one attack occurred for Pigeons AC 1, AC 3, AC 24, and AC 25.

conditions. A comparison of Figures 1 and 2 reveals that rate of attack and number of components with attack generally covaried across all experimental conditions of Pigeons AC 1 and AC 25. Both measures of attack were higher for Bird AC 1 during the last five sessions of the FR schedule conditions than during the last five sessions of exposure to either VT schedule. Similarly, for Pigeon AC 25, both attack measures were higher during the last five sessions of the initial FR schedule condition than during the last five sessions of the subsequent three experimental conditions. Attack rate and components with attack, however, did not consistently covary for the remaining two subjects.

Visual observation during sessions revealed that attacks by Pigeons AC 1, AC 3 , and AC 24 were primarily directed at the eyes, head, and throat areas of the stuffed target. The attack topography of Pigeon $\mathrm{AC} 25$, however, was quite different. For this subject, attack was characterized by discrete pecks as opposed to the bursts of target contacts exhibited by the other birds. This form of attack resembled a grooming or "nibbling" response and frequently did not exceed the force requirement necessary to close the microswitch located beneath the target pigeon. Periodic observation of Bird AC 25 during sessions revealed that exposure to the final three experimental conditions resulted in the progressive reduction of schedule-induced attack responses and a progressive increase in the frequency of "nibbling" responses. Whereas the mean times to the first attack were less than $7.0 \mathrm{sec}$ for Birds AC 1 , $\mathrm{AC} 3$, and $\mathrm{AC} 24$ during all experimental conditions, the same measure ranged from $11.8 \mathrm{sec}$ during the initial experimental condition to $35.1 \mathrm{sec}$ during the final condition for AC 25.

\section{DISCUSSION}

For Pigeons AC 1 and AC 24, a FR food schedule induced a somewhat higher mean rate of attack against a nearby stuffed pigeon than did a VT schedule that was based upon the responsedependent schedule. Whereas Pigeon AC 3 exhibited a lower mean rate of attack during the initial FR schedule condition than during the final three experimental conditions, $\mathrm{Pi}$ geon AC 25 attacked at a higher mean rate during the first FR condition than during the remaining three conditions. The present findings are very similar to those obtained by Cherek et al. (1973) in a comparison of the attack behavior induced by a response-initiated fixed-interval food schedule with that induced by a response-independent fixed-time schedule. These investigators reported that one pigeon attacked at a higher rate during the response-dependent schedule, one bird attacked at approximately the same rate in either schedule condition, and a third pigeon showed a decreased rate of attack across daily experimental sessions. Results similar to those of Pigeons AC 1 and $\mathrm{AC} 24$ in the present study were obtained by Huston and DeSisto (1971) in a comparison of interspecies aggression during FR and FT schedules of reinforcing brain stimulation. Rats killed or attacked more frogs during exposure to the responsedependent schedule than during exposure to the responseindependent condition. Even though the present study and those of Cherek et al. (1973) and Huston and DeSisto (1971) differ from each other in several respects, the results of all three investigations indicate that the inclusion of a response requirement for reinforcement is not a limiting condition, and may even be a facilitating one, for the occurrence of schedule-induced aggression.

Huston and DeSisto (1971) suggest that their fixed-time schedule induced less interspecies aggression than did their FR schedule because the response-independent delivery of brain stimulation may have established superstitious behavior that was incompatible with aggressive responses. In the present study, casual observation during sessions did not reveal the occurrence of any obvious stereotyped patterns of behavior during any experimental condition for Pigeon AC 1 or AC 24, the two birds that attacked at lower rates during the VT schedule than during the FR schedule. Thus, it is unlikely that the responseindependent food schedule induced less aggression for either of these birds because this schedule adventitiously reinforced overt responses that were incompatible with attack.

The schedule-induced attack behavior exhibited by Pigeon AC 25 did not predominantly occur shortly after food delivery and was topographically dissimilar to that exhibited by Pigeons AC 1, AC 3, and AC 24. Because the pecking responses of Bird AC 25 against the stuffed pigeon were often of insufficient force to operate the target microswitch, they also frequently failed to initiate the protective contingency which insured that any criterion attack would not be followed by food delivery for at least $12 \mathrm{sec}$. Thus, it is possible that the lowforce target-oriented behavior of Pigeon AC 25 was adven- 
titiously reinforced during the VT schedule conditions, since the occurrence of such behavior could be closely correlated in time with food delivery. It is unlikely that this behavior was adventitiously reinforced during exposure of Pigeon AC 25 to the FR schedule, since this subject's keypecking behavior, once initiated, continued without interruption until food delivery.

\section{REFERENCES}

Azrin, N. H., Hutchinson, R. R., \& Hake, D. F. Extinction-induced aggression. Journal of the Experimental Analysis of Behavior, 1966, 9, 191-204.

ChereK, D. R., Thompson, T., \& Heistad, G. T. Responding maintained by the opportunity to attack during an interval food reinforcement schedule. Journal of the Experimental Analysis of Behavior, 1973, 19, 113-123.
Cohen, P. S., \& Looney, T. A. Schedule-induced mirror responding in the pigeon. Journal of the Experimental Analysis of Behavior, 1973, 19, 395-408.

Ferster, C. B., \& Sxinner, B. F. Schedules of reinforcement. New York: Appleton-Century-Crofts, 1957.

FLoRY, R. K. Attack behavior as a function of minimum inter-food interval. Journal of the Experimental Analysis of Behavior, 1969, 12, 825-828.

Huston, J. P., \& DeSisto, M. J. Interspecies aggression during fixed-ratio hypothalamic self-stimulation in rats. Physiology and Behavior, 1971, 7, 353-357.

Webbe, F. M., DeWeese, J., \& Malagodi, E. F. Induced attack during multiple fixed-ratio, variable-ratio schedules of reinforcement. Journal of the Experimental Analysis of Behavior, 1974, 22, 197-206.

(Received for publication December 9, 1976.)

\section{ERRATUM}

Kosslyn, S. M., and Matt, A. M. C. If you speak slowly, do people read your prose slowly? Personparticular speech recoding during reading. Bulletin of the Psychonomic Society, 1977, 9 (4), 250-252. Page 250, column 1, Procedure section, the first two sentences should read: "Subjects first simply listened to the conversation. Next, they were asked to read aloud one paragraph; half of the subjects were told that 'Harry, the first person you heard on the tape, wrote it' and half were told that ' $\mathrm{Jim}$, the second person you heard on the tape, wrote it.', 